\title{
Myocardial infarction caused by coronary artery damage from blunt chest injury
}

\author{
S D PRINGLE, K G DAVIDSON \\ From the Departments of Medical Cardiology and Cardiothoracic Surgery, Royal Infirmary, Glasgow
}

SUMMARY A case is reported in which blunt chest injury caused an intimal tear in the left anterior descending coronary artery. Despite few external signs of injury the patient sustained a myocardial infarction resulting in life threatening arrhythmias and considerable left ventricular dysfunction.

Chest trauma is a rare but important cause of cardiac damage. It most commonly results from steering wheel injuries in road traffic accidents ${ }^{1}$ but has also been reported in physical assaults ${ }^{2}$ and as a result of sporting injuries. ${ }^{3}$ Direct injury may cause cardiac rupture, ventricular septal defect, and valvar or myocardial damage. ${ }^{4}$ Less commonly the coronary arteries may be injured. We report a case of anterior myocardial infarction occurring after damage to the intima of the left anterior descending coronary artery.

\section{Case report}

A 20 year old man was admitted to Monklands District General Hospital after a road traffic accident. He had been found wandering confused near his motorcycle which had been in collision with a lamp standard. On arrival at hospital he was fully conscious but disorientated. He had abrasions to his face and right arm, bruising of his anterior chest wall, and a fractured right clavicle. Heart rate was 80 beats/min and blood pressure was $130 / 90 \mathrm{~mm} \mathrm{Hg}$. One hour after admission he developed severe retrosternal pain associated with nausea and sweating. He became hypotensive with a blood pressure of $90 / 60 \mathrm{~mm} \mathrm{Hg}$. An electrocardiogram showed ST elevation in leads V1-V4 consistent with an anteroseptal myocardial infarction. He was transferred to the coronary care unit where electrocardiographic monitoring demonstrated several episodes of nonsustained ventricular tachycardia. The next day he

Requests for reprints to Dr S D Pringle, Department of Medical Cardiology, Royal Infirmary, Glasgow G31 2ER. developed bifascicular block with right bundle branch block and left anterior hemiblock, which progressed to complete heart block requiring temporary transvenous pacing. Echocardiography demonstrated a dilated left ventricle with akinesis of the septum but no pericardial effusion.

Over the next two days the conduction defects resolved and he made an uncomplicated recovery. Substantial myocardial damage was confirmed by a considerable increase in serum creatine kinase (9944 U/1). Cardiac catheterisation six weeks after the accident demonstrated impaired ventricular function with a large anterior akinetic area and a left ventricular end diastolic pressure of $25 \mathrm{~mm} \mathrm{Hg}$. Selective arteriography demonstrated a severe intimal tear of the left anterior descending coronary artery at its origin (figure). The other coronary arteries were normal.

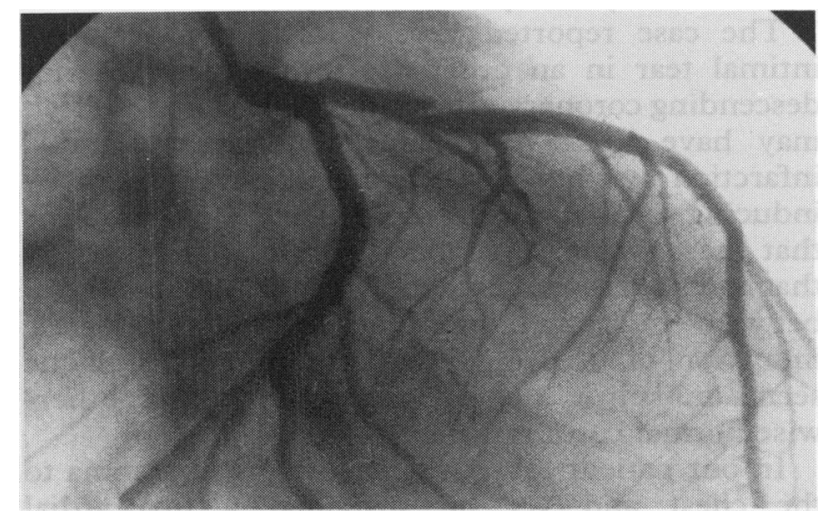

Figure Selective arteriography of the left coronary artery showing an intimal tear of the proximal left anterior descending coronary artery. 


\section{Discussion}

The heart's position between the sternum and the vertebral column makes it liable to injury from non-penetrating chest trauma. This may be more common than previously thought. Non-invasive techniques such as radionuclide angiography have demonstrated cardiac damage in up to $55 \%$ of patients with blunt chest trauma. ${ }^{5}$ Most cardiac injuries are the result of direct trauma to the myocardium causing concussion or contusion. A recent study has suggested that the differentiation between concussion and contusion may be important because the risk of ventricular arrhythmias is increased by contusion. ${ }^{6}$

In addition to direct injury, myocardial infarction may occur as a consequence of damage to the coronary arteries causing lesions ranging in severity from coronary artery rupture and fistula formation to atheromatous plaque fissuring and intimal tears. ${ }^{7}$ These injuries are much less common, accounting for 10 out of 548 patients in one series of fatal chest trauma ${ }^{8}$ and only one out of 258 cases in a prospective study of non-penetrating chest trauma. ${ }^{9}$ Two of these 11 injuries were intimal tears of previously normal arteries. In most previous reports of angiographically proven coronary artery injury in non-fatal chest trauma ${ }^{1011}$ there has been total occlusion of the damaged artery. The assumption is that intimal damage with subsequent thrombotic occlusion occurred. In the presence of a total occlusion, however, it is difficult to be certain about underlying intimal damage. In the two reports in which the artery was not occluded, one had atheroma elsewhere in the coronary tree and this suggests that atheromatous plaque fissuring was the most likely underlying cause. ${ }^{3}$ The other case demonstrated a non-occluded intimal lesion in an otherwise normal right coronary artery. ${ }^{12}$

The case reported here is of a non-occlusive intimal tear in an otherwise normal left anterior descending coronary artery. The intimal lesion itself may have been responsible for the myocardial infarction by causing mechanical obstruction or by inducing local spasm; a more likely explanation is that there was a superadded thrombotic occlusion that had undergone thrombolysis during the interval between infarction and angiography. Traumatic induction of fissuring in an atheromatous plaque seems unlikely in such a young person with an otherwise normal coronary artery tree.

In our patient there were few signs of trauma to the chest and yet he sustained a myocardial infarction with considerable left ventricular damage. As in previous studies, ${ }^{613}$ echocardiography was useful in providing evidence of myocardial damage.
The importance of early recognition is emphasised $\vec{c} . \overrightarrow{.}$ by this case in which there were life threatening arrhythmias and conduction abnormalities that $\stackrel{\mathcal{S}}{\stackrel{\circ}{+}}$ required prompt treatment.

There should be a high index of suspicion of $\frac{\bar{O}}{\bar{O}}$ cardiac injury in all cases of non-penetrating $\frac{\bar{\sigma}}{\vec{\sigma}}$ chest trauma even when there are relatively trivial $\stackrel{\varnothing}{\propto}$ external signs of injury. All such patients should have an electrocardiogram as part of their initial assessment; if this shows changes consistent with myocardial injury we recommend further assessment by echocardiography.

We thank Dr A J S Gardiner and Dr I Hutton for of permission to report this case.

\section{References}

1 Bancewicz J, Yates D. Blunt injury to the heart. Br Med f 1983;186:497-8.

2 Oren A, Bar-Shzomo B, Stern S. Acute coronary‥ occlusion following blunt injury to the chest in the $\vec{P}$ absence of coronary atherosclerosis. Am Heart $\mathcal{F}$ 1976;92:501-5.

3 Watt AH, Stephens MR. Myocardial infarction after blunt chest trauma incurred during rugby football that later required cardiac transplantation. Br Heart f 1986;55:408-10.

4 Tengler ML. The spectrum of myocardial trauma. $f$ 융 Trauma 1985;25:620-7.

5 Sutherland GR, Driedger AA, Holiday RL, Cheung $\overrightarrow{\bar{O}}$ $H W$, Sibbald WJ. Frequency of myocardial injury 3 after blunt chest trauma as evaluated by radionuclide angiography. Am f Cardiol 1984;52:1099-103.

6 Frazee RC, Mucha P, Farnell MB, Miller FA. Objective evaluation of blunt cardiac trauma. $\mathcal{F}$ Trauma 1986;26:510-20.

7 Allen RP, Liedtke AJ. The role of coronary artery injury and perfusion in the development of cardiac contusion secondary to non penetrating chest trauma. $\hat{\rho}$ f Trauma 1979;19:153-6.

8 Parmley LF, Manion WC, Mattingly TW. Non-o penetrating traumatic injury of the heart. Circulation 1958;18:371-96.

9 Mayfield W, Hurley EJ. Blunt cardiac trauma. Am $\mathfrak{Y}$ 을. Surg 1984;148:162-7.

10 Pifarre R, Grieco J, Garibaldi A, Sullivan HJ, MontoyaA, Bakhous $M$. Acute coronary artery occlusion secondary to blunt chest trauma. $\mathcal{F}$ Thorac Cardiovasc ${ }_{\mathrm{WJ}}$ Surg 1982;83:122-5.

11 Stern T, Wolf RY, Reichart B, Harrington OB, Crosby VG. Coronary artery occlusion resulting from blunt trauma. $\mathcal{F} A M A$ 1974;230:1308-9.

12 Oliva PB, Hilgenberg A, McElroy D. Obstruction of the proximal right coronary artery with acute inferior infarction due to blunt chest trauma. Ann Intern Med $\underset{\mathbb{\Phi}}{\circ}$ 1979;91:205-7.

13 Miller SA, Seward JB, Gersh BJ, Tajik A, Mucha P. Two dimensional echo findings in cardiac trauma. Am J Cardiol 1982;50:620-7. 